\title{
Mutaciones de los materiales y las prácticas de lectura en la enseñanza de la Historia hoy
}

\author{
Mutations of Materials and Reading \\ Practices in the Teaching of History Today
}

Marisa Raquel Massone*,

\section{RESUMEN}

Este artículo analiza el papel de los libros de texto y otros materiales escolares en la enseñanza de Historia, en la escuela media en la Ciudad de Buenos Aires, en el marco de una investigación doctoral en curso. Los resultados revelan una profunda transformación de los libros de texto aún en el soporte papel al tiempo que éstos o sus fragmentos fotocopiados en papel siguen teniendo una extraordinaria vigencia. Sin embargo, se combinan cada vez más con una diversidad de materiales en aumento: documentales, páginas web y Wikipedia en orden de importancia. Estas transformaciones están generando mutaciones en las prácticas de lectura en las clases de historia, convirtiendo a los profesores en mediadores de la información histórica entre libros y pantallas.

Palabras clave: libros de texto; materiales escolares; profesores mediadores.

\begin{abstract}
This article analyzes the role of textbooks and other school materials in the teaching of History in the middle school in the City of Buenos Aires as part of an ongoing doctoral research. The results reveal a profound transformation of the textbooks even in the paper support while these or their photocopied fragments on paper continue to have an extraordinary validity. However, they are increasingly combined with a diversity of growing materials: documentaries, web pages and Wikipedia in order of importance. These transformations are generating mutations in reading practices in history classes, turning teachers into mediators of historical information between books and screens.

Keywords: textbooks; school supplies; mediator teachers.
\end{abstract}

Leer y escribir son verbos que se definen en un contexto histórico, a partir de las coordenadas sociales y políticas de una época (Ferreiro, 2001). Estas coordenadas hoy están cambiando. Están cambiando los modos de enseñar y estudiar

\footnotetext{
* Doctoranda con Orientación en Educación, Facultad de Filosofía y Letras, Universidad de Buenos Aires (UBA), Buenos Aires, Argentina. marisamassone@hotmail.com
} 
a partir de la presencia de Internet, la gran biblioteca del siglo XXI, que amplificó los espacios y circuitos de acceso a los saberes, publicando y difundiendo una incalculable cantidad de información de variedad disímil, disponible a través de una diversidad de formas de comunicación (textos, imágenes fijas y en movimiento, sonidos, entre otros), accesibles a gran velocidad. La historia escolar no está ajena a este proceso. Considerando con Cavallo y Chartier que "toda historia de las prácticas de lectura es, pues, necesariamente una historia de los objetos escritos y de las palabras lectoras" (Cavallo; Chartier, 2011, p. 26) me propongo en primer lugar, analizar las transformaciones de los principales objetos de lectura en esta asignatura, los libros de texto. En segundo lugar, las prácticas de lectura en las aulas de historia de la escuela media, reconociendo a los profesores como mediadores y por tanto creadores de los usos de los libros de texto de los que también son lectores. Por último, comparto algunas reflexiones a modo de debates y perspectivas.

\section{UNA MIRADA AL MUNDO DEL TEXTO: CAMBIOS \\ EN EL LIBRO DE TEXTO COMO OBJETO}

Si propusiese a nuestros jóvenes estudiantes bucear hoy en las páginas de un libro de texto de la época de nuestros abuelos, les costaría reconocerlo como tal. De tamaño pequeño y diagramación compacta y poco atractiva, estos libros desplegaban contenidos básicamente a través de textos, muchos de ellos escritos por reconocidos historiadores. Es que en esos primeros tiempos en que la historia se afirmaba como ciencia, algunos historiadores atendieron al mundo de la escuela tanto a partir de la producción de libros de texto como de la formación de estudiantes secundarios o de profesores en instituciones terciarias y universitarias (Finocchio, 2009; Cattaruzza, 2007). Un caso emblemático es el de Levene, quien al mismo tiempo que presidía la Academia Nacional de la Historia divulgaba la narrativa consagrada por el poder en los ámbitos educativos.

Como el resto de los libros de la época, un apretado índice constituía la puerta de entrada de cada capítulo y una narración cronológica se desplegaba a lo alto y lo ancho de sus páginas, interrumpidos por algunos subtítulos y acompañados de unas pocas "láminas", conformadas por mapas, dibujos, pinturas, fotografías o gráficos en páginas separadas. Editados en blanco y negro, 
estos libros del "modelo textual" pertenecientes a la primera generación de libros de texto constituían un material de estudio, valorado por la cantidad y calidad de la información. Diseñados para ser leídos en forma secuencial y estudiados de memoria estos libros casi cabían en la palma de una mano y no contaban con actividades.

Durante décadas, no protagonizaron cambios muy marcados. Con el correr del tiempo, la tecnología off set posibilitó la impresión a dos colores y mayores matices de diagramación aunque el proceso de producción seguía siendo muy lento puesto que los textos seguían elaborándose en máquinas de escribir. Las imágenes tuvieron mayor presencia y se presentaron en medio del entramado de los textos. Usadas como ilustración de la palabra escrita, su inclusión con escasas o nulas referencia acerca del origen de sus fuentes no siempre significó un aporte al aprovechamiento de su valor potencial para favorecer la comprensión. Las actividades crecieron en extensión, básicamente a través de la inclusión de cuestionarios más amplios al final del capítulo.

Estos textos que pasaban de mano en mano de estudiantes y revendedores durante generaciones, constituyeron una evidencia de la transición entre el género "enciclopedia" y el género "unidad didáctica" propio de los libros por venir. Integrados casi en su totalidad por fuentes secundarias, eran distinguidos por el nombre de sus autores. "El libro de 'Ibañez", su nombre circulaba como marca de ediciones de larguísima duración. Elaborados por distinguidos profesores, directores o inspectores, estos libros se produjeron en el marco de una política editorial en la cual a cada disciplina le correspondía una serie de autores legitimados que instauraban y conservaban el saber escolar escrito (Tosi, 2012). Particularmente a partir de 1950 ese saber histórico escolar se mantuvo divorciado de la historia académica. Asimismo, en un contexto de continuidad de la normativa curricular, estos libros incluían algunas marcas de la regulación estatal en su paratexto: "de acuerdo con el programa del segundo año de los colegios nacionales...”. Diversas reglamentaciones y comisiones evaluadoras se convirtieron en espacios de censura particularmente durante los gobiernos militares.

Hacia las décadas de 1980 y 1990 en Argentina los libros de texto constituyeron el cambio en tiempos de profundas reformas educativas. Una combinación de procesos confluyó en la transformación de los modos de organizarlos. Mayor presencia de la imagen y nuevos procesos de producción se hicieron 
presentes de la mano de un boom editorial expresado en la creación de nuevas empresas, muchas de ellas multinacionales. Sin embargo, fue la generación de profundos cambios curriculares de los que los libros de texto fueron sus primeros traductores la que transformó la función misma de estos libros: de materiales de estudio a herramientas de trabajo.

Los textos escolares de historia crecieron en tamaño, tuvieron una diagramación aireada y atractiva a partir de la inclusión de nuevos componentes lingüísticos y gráficos: más títulos y subtítulos en diferentes tipografías, colores, formatos. Los textos “centrales" de las páginas solían ser fuentes secundarias, más cortos que en la primera generación de libros de textos, a los que se sumaban "cuadros de textos" en los laterales con diversas fuentes aportando a una polifonía de voces. Esas fuentes de diverso tipo y naturaleza combinaban fines decorativos, para aliviar los textos largos, propio del modelo acontecimental - institucionalista de la enseñanza de la historia, para ilustrar, ejemplificando o reforzando, aliviando o concretizando la información contenida en los textos centrales para el modelo enciclopedista o el trabajo interpretativo para el modelo globalizante-interpretativo heredero de la historia social (Miguez, 1992), en que las imágenes forman parte de su trama discursiva, muchas veces a través de consignas que las convierten en objetos de lectura.

A la nueva organización discursiva que combinaba el género informativo con otros propios de la comunicación de masas se sumó la fragmentación de contenidos que muchos docentes han vivido como una suerte de video clip. Además, en medio de una apuesta a una historia renovada, con mayor densidad conceptual, la disminución del tamaño de los textos no propició el desarrollo de estrategias narrativas que permitieran superar las crecientes dificultades para la lectura de estos libros que, con una información muy concentrada, suponían un estudiante lector con una "biblioteca" más amplia.

Con normativas curriculares más abiertas y flexibles y ausencia de mecanismos de regulación de contenidos, las editoriales actuaron con grados de mayor autonomía para el diseño de estos nuevos libros. Escritos fundamentalmente por equipos de autores de actualizada formación académica universitaria - en su mayoría egresados de la Universidad de Buenos Aires - y menor formación didáctica y experiencia docente, estos libros han cobijado también la figura del lector crítico, otro/a profesor/a universitario con un recorrido académico mayor al de los autores. Salvo excepciones, poco a poco los autores 
fueron perdiendo autonomía y capacidad de acción. Considerados más bien redactores debieron acatar las prescripciones de la figura cada vez más nodular del editor. Así, los profesores dejaron de referenciarlos como lo hacían en los materiales más tradicionales para identificar ahora los libros por el sello editorial, fuente responsable de la obra (Tosi, 2012).

Al mismo tiempo estos libros han sido de ciclo de vida corta, inaugurando una nueva dinámica anclada en las novedades. Las editoriales respondieron a la pérdida de la centralidad del libro en la enseñanza, al cada vez más extendido uso de fotocopias y a la competencia de sus propios libros usados con una profusa producción que en el caso de algunas editoriales implicaba la oferta de más de un libro de texto por asignatura por año. Esta producción también fue alentada por la fragmentación curricular propia de esos tiempos de reforma educativa de corte académico que tornó necesaria la producción de una variedad de ediciones acordes a las demandas de diversas jurisdicciones y enfoques pedagógicos. Para entonces, mientras el mercado editorial dejaba sin oferta territorios de menor población y potencial económico, el Estado desarrolló el primer antecedente de una política de provisión focalizada de libros de dimensiones nacionales, el Plan Social Educativo (1993 y 1999) (Pascual, 2012).

Para ese momento, las características de los textos de escolares de segunda generación hasta aquí reseñadas se profundizaron con la transición de lo analógico a lo digital. Un proceso de "gran conversión" en el doble plano de lo tecnológico y lo cultural alcanzó al mundo de los libros de tinta y papel (Doueihi, 2010). Por esos mismos días, el relanzamiento del portal Educ.ar en 2003, la creación del canal "Encuentro" por parte del Ministerio de Educación, Ciencia y Tecnología en 2004, la inclusión de los contenidos de la cultura contemporánea en la Ley de Educación Nacional 26.206 de 2006, el establecimiento del Programa Conectar Igualdad en $2010,{ }^{2}$ la generación del canal infantil público y educativo Paka Paka en 2010 y la creación de la plataforma Contenidos Digitales Abiertos (CDA) en 2013 sumados a unas pocas iniciativas de editoriales o colectivos docentes profundizaron un proceso que ya se había iniciado. La generación de textos escolares mimetizados con o metamorfoseados en pantallas (Massone, 2012) se producía al mismo tiempo que una inmensa cantidad de materiales de diferente tipo y naturaleza puestos a disposición de los docentes, para trabajar con ellos online o ser bajados a las computadores y ser usados offline. 
En medio de estos cambios, las nuevas características de los textos escolares pueden palparse desde que se toman los libros en las manos, se observan las imágenes de la tapa o se leen los títulos de las series. En sus páginas se encuentran códigos, títulos de secciones o el diseño gráfico de sus íconos asociados semánticamente con el mundo digital y así se descubren los "deslizamientos entre la cultura impresa y la cultura digital” (Massone, 2012). Esto se expresa, en primer lugar, en una composición propia del hipertexto aún en la materialidad del soporte papel: la página del manual escolar actual se asemeja a la página web. A la yuxtaposición de textos centrales y otros textos e imágenes en las "pastillas" laterales presentes en todas las páginas se suma la permanente intertextualidad que invita a generar diversos itinerarios y lecturas. Además, diversos textos o íconos generan propuestas de articulación de una página con otra que, si bien no son lexías unidas por enlaces electrónicos o links, invitan de todos modos a comportamientos nómadas por parte de los lectores, propios de los hipertextos. En segundo lugar, esos deslizamientos se expresan en un componente multimedial a partir del empleo de diversos lenguajes además del tradicional lenguaje textual, por ejemplo a partir de la inclusión de páginas de historia visual, infografías, propuestas de análisis de películas y, en unos pocos casos, videojuegos. Así, estos nuevos libros presentan el desafío para el tratamiento de diversos lenguajes que no siempre consideran específicamente. En tercer lugar, ese corrimiento de las características de la cultura impresa a la digital también puede detectarse en las diversas propuestas de búsqueda, lectura y escritura en Internet. Los libros de texto suelen incluir propuestas de búsquedas en Internet (algunas caen en la fórmula "busquen en internet" sin brindar orientaciones). También, de lectura de sitios de la red para responder a un microcuestionario sin contextualizar ni analizar su fiabilidad, diferenciando páginas .com de .edu o .gov o sin detallar si se va a leer una fuente primaria o secundaria, por ejemplo. En algunas series más nuevas esta dilatación del libro hacia el espacio virtual se manifiesta a partir de la impresión de códigos QR para continuar trabajando en el espacio digital, particularmente con materiales audiovisuales. En algún caso, los libros incluyen orientaciones generales sobre búsquedas en Internet como parte de "técnicas para aprender historia". Estas nuevas propiedades redefinieron la categorización de los manuales escolares como tipos de textos cerrados generada por Eco (1981). Por último, los 
nuevos libros incluyeron secciones específicas vinculadas con el uso de TIC o de Internet: se generan a través de diversas presentaciones como la diferenciación entre nuevos y viejos modos de conocer de la disciplina como por ejemplo, "Nuevas herramientas de la Historia" que propone visitar un museo virtual y "Herramientas de la Historia" que ofrece propuestas de análisis documentos escritos. También, "proyectos integradores colaborativos con el uso de TIC”, entre otros formatos.

Estos libros son contemporáneos de las políticas de ampliación y manejo de las TIC y de distribución de libros por parte del Estado Nacional, de la mano de la implementación del Programa Nacional de Becas Estudiantiles (PNBE) destinado a las escuelas más desfavorecidas en términos socioeconómicos y recomendados por la Comisión Asesora Nacional (CAN) formada por especialistas designados por cada una de las jurisdicciones y sus homónimas provinciales.

En los últimos años, ante la consolidación de la cultura digital, las editoriales tomaron la decisión de ampliar su oferta de libros de texto. “Tendremos que pensar mucho menos en productos y mucho más en contenidos; tendremos que concebir 'el libro' como una estructura nuclear o básica, pero quizás con los bordes mucho más porosos que antes", señala Raguseo (2013, p. 7) citando a una editora de una editorial multinacional. Es así que las editoriales han expandido, ampliado o enriquecido el libro de texto impreso hacia y a través de plataformas virtuales que ofrecen desde versiones digitales de los libros impresos o actividades complementarias hasta soluciones integrales para la administración de la educación, destinados a estudiantes, profesores, familias y escuelas que, seguramente, están dando origen a nuevas prácticas. Los libros digitales son alojados físicamente en los servidores de las editoriales y sólo pueden ser adquiridos junto a la compra de libros impresos. Se trata de libros híbridos en los cuales "la dimensión electrónica crea algo nuevo para la escritura histórica; es como si pudiésemos oír el pasado" (Darnton, en Friera, 2015). Así, estudiantes y profesores pueden escuchar audios, ver videos o animaciones, leer documentos, acceder a enlaces de la web, realizar actividades interactivas o aún contar con evaluaciones, desafiando la noción de "un texto unitario y permanente" (Landow, en Lion; Perosi, 2012). 


\section{UNA MIRADA AL MUNDO DE LOS LECTORES:}

\section{LAS PRÁCTICAS DE LECTURA DE LIBROS DE TEXTO}

Hasta aquí he reconstruido las transformaciones del mundo del texto. La labor ahora es entrelazarlo con el mundo de los lectores, una tarea que "exige, ante todo, tener en cuenta que sus respectivos significados dependen de las formas y las circunstancias a través de las cuales sus lectores (o sus oyentes) los reciben y se los apropian" (Cavallo; Chartier, 2011, p. 26). Esto implica desentrañar cómo se lee en diversos contextos escolares en los cuales el espacio, la luz, el mobiliario y los útiles disponibles condicionan y orientan las maneras de hacerlo, tal como revela Rockwell (2001). También cómo en el aula la lectura se transforma en un acto social en el cual, lejos de la concepción 'moderna' de lectura individual y silenciosa, se lee siempre en medio de un continuo intercambio oral en el cual intervienen otros sujetos que contribuyen a determinar los actos de interpretación. El alumno no está sólo frente al texto, es decir, hay una producción oral que acompaña al acto de leer. El docente siempre media el acto de lectura. Selecciona, lee, expande, orienta, replantea, desecha, contradice los contenidos de los textos a través de diversas intervenciones y/o consignas, transmitidas oralmente o en forma escrita. Asimismo, puede enmarcar las prácticas de lectura privilegiando un género discursivo en vez de otro. Al mismo tiempo, las intervenciones de otros alumnos que comparten sus interpretaciones también inciden en la lectura de cada uno.

En las aulas de Historia, el texto escolar siempre ha tenido una presencia muy viva. La adhesión al libro de texto ha sido una característica de los profesores de historia de todos los tiempos. En Argentina, el informe elaborado a pedido del Ministerio de Instrucción Pública por A. Dellepiane en 1903 subraya esa centralidad:

El método tradicionalmente usado en nuestros institutos secundarios, públicos y privados, para la enseñanza de la historia, consiste en adoptar un manual [...] como libro de texto, y en obligar a los alumnos a estudiarlo, por dosis, en sus casas, para recitarlo en la clase ante los condiscípulos y el profesor, quien suele agregar algunos comentarios y ampliaciones. (Dellepiane, 1903, en Lanza; Finocchio, 1993, p. 141) 
Un libro para aprender historia de memoria, para dar lección. Un libro como partitura del docente al cual éste podía agregar comentarios y ampliaciones. Otras fuentes ratifican ese lugar central del libro en las clases. Se trata de entrevistas a usuarios de libros de texto en la escuela secundaria en distintos períodos extraídos de la tesis doctoral de Tosi (2012). La autora indaga sobre el uso de libros de texto en la escuela secundaria en general y solicita detalles sobre su uso a partir de la pregunta “¿podés contar cómo se usaba un libro en una materia que elijas?”. Según la mayoría de los estudiantes entrevistados que cursaron entre 1960 y 1982, las clases se estructuraban libro en mano, un lugar central que continuaba en el estudio del tema en el hogar o en la biblioteca. Las expresiones, "saquen los libros” y el señalamiento de páginas particulares eran las instrucciones más comunes.

La que me acuerdo era Historia. No me gustaba. En esos tiempos, la Historia era: “Estudien de la página 241 a la 265". Hasta las notas que estaban debajo de la hoja nos tomaba la profesora y no explicaba mucho de lo que pasaba en esas hojas. Nos tomaban lección y, después, el resto de la clase era una especie de hacer cuadros sinópticos y contestar un cuestionario que estaba en el libro y que correspondía al tema que estaba ahí. En realidad, en ese entonces era una obligación cada uno de los alumnos teníamos los libros que necesitábamos, no había fotocopiadoras - Mujer. Período de cursada de Secundario: 1960-1964. Lugar: Avellaneda, provincia de Buenos Aires. (Tosi, 2012, p. 454)

Las entrevistas a usuarios de libros que cursaron su escuela secundaria entre 1983 y 2006, ya en un nuevo contexto, dan cuenta de una cantidad menor de libros presentes en las clases, aunque las prácticas lectoras eran similares. Leer para resumir o responder preguntas. Leer particularmente los textos de esos libros, sin considerar otras fuentes.

Voy a hacer referencia al libro de texto que usé en Historia. No considero que haya sido una experiencia muy productiva. El libro era interesante pero la manera de manejarse de la profesora quizás fue lo que no me gustó. Se leía cada texto y no se analizaba mucho más que lo escrito allí y a continuación teníamos que hacer un resumen de lo leído o, en algunas ocasiones, utilizábamos las preguntas que él mismo libro traía. Me pareció que no aprovechamos, por ejemplo, la parte de documentales, entrevistas o noticias que se encontraba a finalizar cada tema. 
Por supuesto, al momento de estudiar, mi relación con el texto fue otra - Mujer. Período de cursada de Secundario: 2002/2006. Lugar: Tandil, provincia de Buenos Aires. (Tosi, 2012, p. 466)

Pocas voces de intercambio acerca de lo que se iba a leer o se había leído, escasa socialización de interpretaciones. El libro seguía siendo el material principal que organizaba la clase, para leer en voz alta, responder al cuestionario, escribir un resumen o hacer actividades. Ha sido tal la importancia del libro de texto a lo largo del tiempo y en diversas latitudes en las prácticas escolares que el historiador español Agustín Escolano (2006) lo ha denominado currículum editado porque traduce lo normativo al texto y genera una gran incidencia en la selección y secuencia de contenidos a enseñar y las estrategias pedagógicas utilizadas de una disciplina (Romero, 2011). Entonces, partiendo de la certeza de que era la principal fuente de lectura prescripta por los profesores, se convirtió en el objeto más estudiado de la didáctica de la historia. Estos estudios, generados desde la perspectiva del análisis de textos, hicieron foco en el enunciado ("lo que dice") y la enunciación ("la manera de decir") de los libros. Así las investigaciones examinaron en mayor medida, su contenido e ideología y en menor, sus procesos de elaboración y distribución. Sin embargo, considerando el estado actual de las investigaciones sobre textos escolares, sostengo con Valls que

ya no es suficiente abordar el estudio de los manuales [...] como si fuesen objetos autónomos o cuasi-independientes, sino que los manuales escolares exigen ser considerados necesariamente en su relación tanto con los alumnos como con los docentes y que ambas relaciones son profundamente complejas y que son diversas en función de la disciplina escolar de la que se trate. (Valls Montés, 2001, p. 2)

Es necesario considerarlos en relación con los estudiantes, los docentes y también las familias, en función del lugar que ocupan en la configuración de la disciplina escolar, la interacción con otros materiales escolares, las condiciones de acceso y apropiación generadas por las políticas educativas, el mercado y la cultura escolar de cada nivel educativo y cada espacio escolar. Es que los textos escolares son un producto cultural intervenido, no sólo por las intenciones "culturales" de sus productores o por los sistemas de control que regulan la denominada "policía" del libro, como en parte he reseñado más arriba, 
sino por los criterios "culturales" de quienes lo seleccionan y usan (Escolano, 2012). Coordenadas individuales y colectivas se van cruzando en las prácticas de uso de los libros de texto. Se trata de coordenadas que van cambiando a lo largo de la biografía profesional, los saberes conquistados a través de la socialización profesional, la propia experiencia, las instancias de formación inicial y continua transitadas y las propias búsquedas. Pero particularmente de otras vinculadas con el contexto en que los profesores desarrollan su labor. En cada escuela, sus elecciones están marcadas por decisiones institucionales en las que su voz es importante pero no la única: los equipos directivos y/o los colegas docentes o bibliotecarios también juegan un papel importante. Igualmente por las condiciones materiales de las escuelas, dependientes de los planes de provisión de libros de texto o las posibilidades económicas de las familias. Considerando estas múltiples variables, los profesores deciden qué libros de texto utilizan y prescriben, las formas concretas de su uso, tanto en el aula como en el hogar. De igual forma, los estudiantes los "consumen" para estudiar, hacer ejercicios y actividades, condicionados por dichas prescripciones (Adell; Bernabé, 2006).

Poner la mirada en los cambios de las prácticas de enseñanza de la lectura y la escritura en la enseñanza de la historia me ha implicado estudiar las acciones de los docentes como mediadores entre libros y estudiantes, atendiendo no sólo a la pregunta qué dan de leer y escribir sino cómo y con qué sentido lo hacen en su propio territorio, en forma situada. Por estas razones es que consideré la adopción de una metodología cualitativa alineada al paradigma interpretativo (Vasilachis, 2006). Por un lado, he generado un primer acercamiento a las prácticas docentes a través de encuestas semicerradas realizadas, en la mayoría de los casos, de manera personal y conversacional, para luego hacer foco en la observación de escenas de aula, el análisis de carpetas y la realización de entrevistas en profundidad a profesores de seis estudios de casos - tres de escuelas de gestión pública y tres, de privada. En este trabajo voy a compartir los resultados de las encuestas y los estudios de casos vinculados a las escuelas de gestión pública, un contexto singular para reconstruir la cultura de sus enseñantes.

A partir de una encuesta realizada a sesenta profesores de escuelas medias públicas de CABA durante los años 2015 y 2016 he indagado sobre los materiales que los profesores de historia de diferentes edades ofrecen a los 
estudiantes, tanto para los inicios de su profesión como para los tiempos actuales. Sus respuestas evidencian la extraordinaria vigencia del uso de libros de texto. Sin embargo, esta presencia adquiere muy diversos modos, no tanto a partir de la obtención de ejemplares de estos materiales sino particularmente a través del uso de fotocopias de uno o más libros. También se genera a partir de la consulta de ejemplares en la biblioteca escolar, muchas veces compartidos con otros estudiantes en propuestas de trabajo grupal. Además, los libros se usan como material de apoyo y referencia para el docente.

En general, en nuestro país los docentes tienen autonomía para elegir los materiales a utilizar en la enseñanza. También, para decidir qué libro de texto utilizar. Es así frecuente observar la utilización de libros de diversos formatos y editoriales tanto en distintas escuelas como aulas de una misma institución. Igualmente, el uso de libros de textos adquiere sentidos diferentes en los distintos momentos del año escolar. Así lo explica Gabriela, una de las profesoras entrevistadas que desarrolla su labor en una escuela que atiende a estudiantes provenientes de sectores medios y bajos:

Sí uso los manuales, digamos, sobre todo para armar el programa. Una vez que armo el programa ahí si, después voy revisando "a ver, esto me sirve, esto no me sirve". Y lo que trato de buscar en los libros, más que nada, es el tema de las fuentes porque, por ahí, en libros de manuales de Historia lo que tienen es muchas fuentes interesantes para trabajar con los chicos. Yo voy adaptando, "esto me sirve, esto no me sirve". (Entrevista realizada el 14 marzo 2018)

El uso del libro para armar la programación lo convierte en un importante recurso de instrucción, aunque seguramente no es el único. Así, tal como conceptualiza Martínez Bonafé y Rodríguez Rodríguez (2010), "el libro de texto se utiliza como el currículum presente", como una herramienta combinada con otros materiales. Pero ese uso no copia el protocolo de lectura desarrollado por sus editores y autores, si no que forja una práctica de lectura exploratoria orientada por diversas inquietudes. La "caza furtiva de fuentes", usando la metáfora de Michel de Certeau (2007, p. 187) sobre los lectores-viajeros que "circulan en tierras ajenas, nómadas que cazan furtivamente a través de los campos que no han escrito ellos, arrebatándose los bienes de Egipto para disfrutarlos", priorizando la apropiación de documentos escritos, herencia del "culto a los documentos" propio de la formación academicista de los 
profesores. También la consideración de las exigencias curriculares emanadas de las autoridades educativas y de igual forma la atención a la propia experiencia, tal como propone la misma profesora:

El año pasado, en todas las escuelas hubo como una bajada de línea que en todas las planificaciones anuales tiene que haber una actividad de $\mathrm{ESI}^{3} \mathrm{y}$ una actividad que incluye nuevas tecnologías. Entonces, ahí también, más allá de usar libros tengo que estar pensando en qué contenido puedo incorporar las nuevas tecnologías. A veces, los manuales ayudan porque tienen unos videos, algunos links que te sugieren algunas actividades para trabajar con los chicos. Pero, en general, me baso más que nada en la planificación del año anterior y en la experiencia del año anterior. Lo que me funcionó, lo que no me funcionó y en función de eso, también voy revisando el material que tengo que darle a los chicos. (Entrevista realizada el 14 marzo 2018)

La creciente sensibilización de los y las jóvenes por la cuestión de género al grito del Movimiento "Ni una menos" (http://niunamenos.com.ar/) emergido en 2015 reactualizó y dio impulso a la Ley 26150 de Educación Sexual Integral (ESI), una demanda curricular que si bien estaba vigente desde hacía más de diez años hoy se traslada a la selección de libros de texto. Otra búsqueda está asociada con la demanda de inclusión de las TIC. Asimismo, considerando a las prácticas de la enseñanza de la lectura y la escritura como artes de hacer más guiadas por obligaciones prácticas que por lógicas teóricas, la profesora selecciona el material considerando lo que le funcionó, lo que le dio resultado, según sus propósitos.

Esas búsquedas también pueden estar asociadas a preguntas propias, vinculadas con los recortes de contenidos a desarrollar, tal como expresa Pilar, otra de las profesoras entrevistadas que desarrolla su labor en una escuela pública dependiente de la UBA:

Lo que hago en general es ver varios, los que tengo a mano, los que pueda, para ver por dónde viene la mano, cómo se trabajan algunos temas y qué temas se trabajan, eso lo suelo hacer bastante y lo hice el año pasado pero como una inquietud mía. Para tercero busco en general pensar proyectos de Nación, los proyectos en disputa. En base a eso voy a mirar los libros de texto, me fijo incluso si hay alguna pregunta parecida a la mía y tomo cosas que me parecen piolas (por 
ahí son capítulos enteros, a veces son cachitos). En general trato de pensar el programa entero, con alguna cosa que me permita darle sentido a todo lo demás porque si no tiendo a ramificar mucho, esto me parece interesante y esto también, todo me termina pareciendo interesante. Y en términos pedagógicos, me resulta mucho mejor tener una cuestión fuerte conceptual mía y después ir navegando. (Entrevista realizada el 5 marzo 2018)

El libro se valora como una herramienta que se tiene a mano y sirve para orientarse "para ver por dónde viene la mano". Se trata también de una lectura exploratoria atenta a la selección y el tratamiento de los temas de la historia escolar. Pero en esta mirada se entrecruza otro propósito, propio del docente, "una cuestión fuerte conceptual mía", una pregunta de la enseñanza que define un sentido particular a estos contenidos, una decisión curricular.

Estas decisiones se generan en un contexto particular, el de la mayor parte de las escuelas públicas de la CABA, que condiciona la compra de libros. Se trata de una tradición arraigada en la cual se entrecruzan diversas variables. Muchos profesores no piden libros anclados en sus propias concepciones sobre los libros de texto. Críticos del texto único, entienden el uso de fotocopias como el medio para incluir diversas voces y debates en la enseñanza de la historia. También consideran el uso del libro les quita protagonismo a sí mismos y a los estudiantes en el proceso de enseñanza y aprendizaje (Verón, 1999). Asimismo, dudan sobre sus posibilidades de aprovechamiento, vinculadas con una reducción del tiempo de enseñanza de esta asignatura ${ }^{4}$ y la subutilización de los libros para los cuales las familias deben hacer una importante inversión. Además, el reglamento escolar de la CABA establece en su artículo 50 que las autoridades de las escuelas dependientes del Gobierno de la Ciudad de Buenos Aires no podrán exigir a los alumnos, entre otras cosas, libros de texto de determinada editorial. Si bien este reglamento no se cumple al pie de la letra, los profesores expresan que muchos de sus alumnos no están en condiciones de comprarlos, porque efectivamente es así o porque se instaló ese imaginario reflejo de los peores tiempos de crisis de nuestro país. E igualmente porque mientras los profesores suelen adoptar el mismo libro en el cual confían por un largo período de tiempo, el mercado editorial produce libros con escasos años en "catálogo", lo cual imposibilita conseguirlos usados para todos los estudiantes de un aula. Es así como en su reemplazo, ofrecen fragmentos de 
libros copiados a los que suma otros materiales de elaboración personal. Se trata de continuar teniendo como referente a los libros generando una relectura de los mismos (Martínez Varcacel et al., 2012) o produciendo un nuevo libro, a partir de un uso y reproducción particular, diferente al generado por autores, editores y evaluadores (Silva, 2012).

El libro también puede constituirse en un refugio tanto para los estudiantes como para los profesores, cuando están empezando la escuela media, los temas a enseñar no son tan del gusto o la formación del docente, como explica Pilar cuando le pregunto sobre el uso de libros en el armado del día a día de las clases:

En primero usaba mucho más que en tercero, que utilizaba más estas preguntas como disparadoras, que me salen más naturales con el contenido de tercero quizá porque me interesa más que el de primero. En primero soy mucho más cercana al libro de texto, también porque para el estudiante es una tranquilidad, hay muy buenos libros de texto. También, a mí el contenido me cuesta un poco más como entrarle - después con los años le fui encontrando algunas entradas y me organiza el libro a mí en primero [...] En primero, trato de seguir un orden que después ellos puedan encontrar en el libro porque me pasaba que, cuanto yo menos seguía ese orden del libro, mas perdidos estaban. Así que trataba de seguir a grandes rasgos el hilo de continuidad que planteaba el texto. (Entrevista realizada el 5 marzo 2018)

Asimismo, en la crítica a la condensación de la información propia de los libros de texto de las últimas décadas, la selección de sus fotocopias se combina con otros textos, académicos o de divulgación, como en el caso de las clases de Gabriela:

Cada vez es más acotada la información y da muchas cosas por entendidas que los chicos no llegan a entender el proceso. Entonces, trato de ver bien qué manual usar y, en vez de usar manuales, muchas veces prefiero usar libros, libros de Historia. El año pasado usamos algunos del CBC, de UBA XXI. ${ }^{5}$ (Nota de observadora, 12 mayo 2017)

Las fotocopias constituyen un "paquete" de materiales de diversos orígenes, tanto fuentes primarias como secundarias, un "comprimido de saberes" copiados 
de diversos libros no siempre distinguibles. Es que "en el magisterio lector se recomiendan los libros básicamente con referencia a su contenido. Los datos del autor generalmente importan poco" (Rockwell, 1992, p. 48). En las clases observadas de esta misma profesora, ésta ofrece a sus alumnos una mixtura de fotocopias provenientes de cuatro textos escolares distintos sumados a fragmentos de dos textos académicos - uno de ellos utilizado en clases del CBC de la UBA -, resúmenes tipeados o manuscritos preparados por ella misma, algunos documentos escritos extraídos de Internet y unos pocos mapas.

Para los distintos casos estudiados, se producen diferencias en el recorte realizado de los textos escolares. Hay profesores que ofrecen la lectura de capítulos completos mientras que otros, de páginas sueltas o fragmentos de esas páginas pegadas a modo de patchware en una hoja fotocopiable. Al mismo tiempo, ese uso es en ocasiones diferenciado según el grupo de estudiantes. En las conversaciones que los profesores fueron protagonizando en medio de las preguntas de las encuestas así como en el caso de la profesora Pilar, ese uso de libros de texto se concentra particularmente en los estudiantes de los años superiores de la escuela media, reservándose para los de los primeros años el uso de un ejemplar de un libro de texto porque les resultaba más ordenador. Es que producidos para regular la acción de los usuarios, los libros de texto presentan contenidos de manera organizada y dosificada.

Esos fragmentos de textos se usan en formato impreso y digital, a través de un campus virtual, una red social, grupos de WhatsApp del grupo clase o el celular de cada uno de los estudiantes. Desde hace muchos años, el uso de fotocopias ha resultado tanto una alternativa ante la falta de libros como un medio para democratizar el acceso a diversos materiales escolares. Resulta interesante interrogar esta práctica a partir de la posición adoptada por el historiador de la lectura Jean Hébrard (2000) respecto de lo que llama cultura del "dossier de fotocopias", en coincidencia con las decisiones de algunos profesores:

Lo que sale de la fotocopiadora es un saber que ha perdido su vínculo con lo que lo rodea, un saber de lectura muy difícil porque uno no tiene lo anterior y lo posterior a lo que está leyendo. Estamos muy contentos cuando fotocopiamos grupos de copias para los chicos, el "dossier" es una pedagogía muy moderna, pero no los ayudamos con ese tipo de material. Para ellos es mucho más fácil el 
manual, porque éste le da la continuidad del saber. Y si se olvidaron de algo, pueden volver atrás. Si imaginan un desarrollo de lo que están viendo, pueden ver los capítulos siguientes.

Asimismo, en las observaciones de clase y análisis de carpetas de alumnos he detectado que las fotocopias, en casi todos los casos, se convierten en los objetos de lectura. Se "sacan", se "leen", se "guardan" sin aludir a su origen, el libro del que fue copiado (su/s autor/es, su editorial, fecha y lugar de edición) o simplemente aludiendo a ellas en las consignas de las carpetas. Las fotocopias constituyen un soporte de lectura legitimado en las prácticas escolares, un compendio de textos anónimos, textos leídos sin contexto. Desaparece el enunciador, un problema particularmente para la enseñanza de la historia porque obstaculiza el trabajo con el principio de la multiperspectiva de los actores o los científicos sociales. Estas prácticas están asociadas a una nueva pedagogía que considera las fotocopias "despiertan menor temor que un libro y aparecen como aptas para una apropiación más fácil” (Verón, 1999, p. 124).

Como he descripto más arriba estas prácticas también se explican en relación a lo que en su estudio sobre los maestros en México Elsie Rockwell (1992) llama "usos particulares de la lengua escrita", vinculados con las condiciones materiales e institucionales que los generan. Como señalaba junto a otras colegas en otro trabajo, la acción y los saberes de la práctica docente determinan sus formas de leer. Los libros de texto junto con las revistas no suelen acumularse en los armarios sino que circulan y se difunden entre colegas, no como referencias bibliográficas sino como herramientas necesarias para la enseñanza (Ayuso; Massone; Romero, 2012). Es en este sentido de uso que circulan las fotocopias de libros de textos en las aulas de historia, como parte de una búsqueda permanente y deliberada, aunque de manera fragmentaria y a veces implícita, de materiales impresos que puedan apoyar la propia tarea de enseñar (Rockwell, 1992), tal como surge del registro de observaciones de clases de Gabriela: "la profesora invita a sacar las fotocopias, las de Revolución de Mayo, y las presenta a los alumnos diciendo: 'tienen una mezcla de apuntes míos, de un manual y tienen un cuadrito como éste' (lo muestra)” (Nota de observadora, 12 mayo 2017).

Asimismo, las observaciones de clase de los tres casos estudiados me han permitido detectar que se han generado pocos momentos de lectura de libros 
de textos o paquetes fotocopiados durante las clases, situación que una de las profesoras explica por la reducción de la carga horaria de la materia a partir de la implementación de la NES. Seguramente constreñidos por el tiempo, una dimensión necesaria para dar cuenta de la trama de acciones que dan forma a las prácticas y a la vez expresan la cultura escolar, los profesores observados han priorizado la lectura en clase de documentos escritos, justamente uno de los objetos de lectura particularmente seleccionados de los libros. También, la lectura de las fotocopias como una tarea para el hogar, una tradición ya presente en los recuerdos de estudiantes analizados más arriba. Estas prácticas reflejan al mismo tiempo que afianzan una característica constitutiva de la cultura escolar de la escuela media en la que, a diferencia de la de la escuela primaria en que el/la maestro/a ha acostumbrado a sus alumnos a la lectura colectiva, verbalizada y acompañada paso a paso por él mismo, los alumnos deben leer y explicar en soledad.

La persistente presencia de materiales impresos, en menor medida en forma de libros y en mayor, en fotocopias, me ha generado algunos interrogantes. Parafraseando a una de las docentes entrevistadas por Martínez Varcacel y otros (2012), pasar del interrogante “¿qué debería tener un libro?” a “¿qué tiene que saber sacar el profesor del libro?”. En función de esta consideración, me pregunto ¿cuál es el peso de los saberes sobre la lectura de los profesores en las prácticas lectoras generadas en clase? ¿y de los saberes historiográficos? ¿qué saberes son necesarios para "abrir" el texto escolar a otras lecturas?

Si en la Historia como disciplina escolar, desde hace algunos años, el mundo de los libros impresos viene problematizándose a partir de la pedagogía del dossier de fotocopias, hoy, esa centralidad del libro en la transmisión cultural se ve interpelada por la existencia de Google, Wikipedia o de numerosos sitios web de información histórica disponibles en Internet las 24 horas, todos los días del año. Como una biblioteca gigante, Internet se convierte en el lugar para buscar información y materiales didácticos. Si bien algunos profesores encuestados se reconocen usuarios de Wikipedia, los sitios de Encuentro, Educ.ar y Conectar Igualdad fueron reconocidos como los más visitados, signo de la confianza en una autoridad que viene de la política educativa. Asimismo estos profesores señalan que cambiaron los materiales que dan de leer a sus estudiantes en los últimos años. Es así que comenzaron a combinar el uso de textos escolares o sus fragmentos fotocopiados con documentales, páginas web 
y con la enciclopedia digital y colaborativa Wikipedia, en orden de importancia. La historia en imágenes, especialmente los documentales, está ocupando un protagonismo mayor en las clases de historia. Una gran mayoría de profesores reconoce su uso como material educativo vistos en y extraídos de Canal Encuentro o sus reproducciones en YouTube. Se trata de documentales organizados en treinta minutos como medida única de tiempo - una razón clave para su utilización en la escuela - y producidos para un público más general que han adoptado ciertas características del género periodístico y sostuvieron un afán de entretenimiento, fusionando la voz de las "cabezas parlantes" de especialistas con dramatizaciones, ficcionalizaciones o personajes que narran en primera persona, en una diversidad de formatos, guiones y estilos (Ibarra, 2013). Su presentación en el canal estatal ha incluido también la recomendación de materiales bibliográficos y propuestas de enseñanza y la posibilidad de descargarlos y ofrecerlos como material de lectura en diferentes momentos y con distintas continuidades en las clases de historia, incluida su link en un blog, Facebook escolar, como en dos de los casos estudiados o simplemente recomendados en un trabajo práctico en versiones impresas o digitales. Es indudable que variados registros propios de la televisión están entrando con más fuerza a la escuela (Dussel, 2016), un cambio que no resulta menor. Asimismo, una extensa mayoría de los profesores encuestados asegura solicitar a sus alumnos la búsqueda autónoma de información en Internet y/o la realización de tareas utilizando sitios de Internet seleccionados por los estudiantes. Así, los profesores se enfrentan al desafío de un cambio en quién toma las decisiones sobre los materiales de estudio: ya no quedan exclusivamente en manos de los docentes, ahora están también involucrados los estudiantes (Perelman, 2013). Los profesores tienen ahora menor control del que creían tener cuando los estudiantes consultaban libros, enciclopedias o revistas de divulgación. También, del modo en que se ejercen esas consultas. Es por eso que gran parte de estos profesores orientan esas búsquedas autónomas de información histórica de muy diversos modos, desde la sugerencia de páginas, videos o autores, acotando la búsqueda a partir de algunos sitios "indicándoles los posibles lugares donde buscar”, guiándolos en relación con los buscadores o especificando palabras clave y conectores o conceptos para la búsqueda, solicitando el listado y o los links de las fuentes consultadas, revisando su pertinencia con los alumnos, "corrigiéndolas con la web" o explicando "las extensiones de los 
sitios web más confiables .edu .gov .org”. Otros, "desde un abordaje proteccionista, con el fin de 'proteger a los niños y jóvenes de las influencias negativas de los medios de comunicación"” (Morduchowicz, 2008, p. 151), sugiriendo los sitios no recomendados, especificando "qué sitios no visitar".

Lo expuesto da que cuenta que si bien nadie acabará con los libros, tal como pronosticaban Jean-Claude Carrière y Umberto Eco en su libro de 2010, es cierto que "los libros de texto están, cada día, más lejos de ser el único referente posible para el trabajo didáctico" (Díaz Argüero, 2008, p. 199). Se están generando nuevos caminos para el acceso y la apropiación del conocimiento propios de la cultura digital que están redefiniendo su lugar privilegiado en el universo de los materiales escolares.

\section{DE FUTUROS Y PERSPECTIVAS}

Esta aproximación a los objetos y las prácticas de lectura en la enseñanza de la historia es sólo una muestra de una historia escolar en movimiento. Del modelo textual al libro híbrido pasando por el libro multimedial y metamorfoseado en pantallas, el libro de texto ha cambiado no sólo en su propia naturaleza sino también en el modo en que profesores y estudiantes acceden a y se apropian del mismo.

En un contexto como el de la Argentina que, a diferencia de Brasil y otros países latinoamericanos, posee una joven y zigzagueante tradición de políticas de provisión estatal de libros de texto ${ }^{6}$, unas particulares características de su mercado editorial y una profusa producción estatal de materiales digitales, los profesores redefinen el papel de estos libros como objetos didácticos en sus clases a partir de diversas preguntas de la práctica: ¿seleccionar un libro de texto o trabajar con fotocopias de varios libros? ¿poseer el libro de texto o tener acceso al mismo en biblioteca? ¿tener un ejemplar del mismo título para cada estudiante o contar con algunos libros para compartir entre varios? ¿trabajar con un libro de texto único o con una diversidad de libros de texto disponibles? ¿usar sólo libros o complementarlos con otros materiales impresos (libros de divulgación o textos académicos) o digitales? ¿usar el libro conocido, ya experimentado, o uno nuevo, recién editado?

En los casos analizados, la enseñanza se sigue apoyando principalmente en la utilización de libros de texto, un material con el que los profesores 
contaron incluso antes del pizarrón y con el que los estudiantes tienen la posibilidad de aprender la "cultura del libro". Hoy los profesores ofrecen esta pieza crucial de la cultura impresa - muchas veces la única que ingresa a los hogares de los estudiantes - como una herramienta básica e inacabada, a modo de compilado de fragmentos de capítulos, páginas o trozos de páginas fotocopiados, en general, a medida que se va avanzando en el estudio de los temas, de modo "suelto". Las fotocopias continúan la tradición del trabajo con un libro único. Reproducidas en blanco y negro y con poca definición en la calidad de sus imágenes, suelen organizarse sólo para su uso cotidiano durante las clases, difícilmente se guardan luego de ser subrayadas y se extravían con facilidad, convirtiéndose así en materiales efímeros que, a diferencia de los libros que pueden permanecer "como remanente y recordatorio de los años escolares transcurridos" (Eco, 2004), no dejan rastro en la memoria. Asimismo, el armado de una carpeta de recortes de libros de textos carece de un enunciador identificable o posee "tantos enunciadores que en verdad pareciera que no hubiese ninguno" (Verón, 1999, p. 146), homologando ciertas lecturas descontextualizadas del océano tumultuoso de la información que es Internet. Al mismo tiempo, estas copias de libros de texto se combinan, cada vez más, con el visionado de algunos documentales, la lectura de páginas web, Wikipedia y la lectura exploratoria de Internet para la cual los profesores generan algunas orientaciones, guiados más por obligaciones prácticas que por lógicas teóricas, tal como sostiene Chartier, siguiendo a De Certeau. De estas diversas formas los profesores de historia indagados se apropian de o leen o reescriben los libros de texto. En este panorama, está claro que:

Trabajar en un contexto donde el libro es el único referente para abordar un contenido específico es muy distinto a hacerlo donde existe una biblioteca en el aula o en la escuela, acervos electrónicos y conectividad a Internet. No es lo mismo tener una fuente única de información que contar con fuentes múltiples que aportan información distinta sobre un mismo tema. La diferencia introduce, riqueza y complejidad. (Díaz Argüero, 2008, p. 189)

En este contexto, es importante comprender que la incorporación de nuevos medios a la enseñanza no constituye una ventaja per se sino que plantea nuevos desafíos a docentes y estudiantes, por ejemplo, integrar información procedente de diversas fuentes (Díaz Argüero, 2008). Este desafío implica 
redefinir los saberes propios de quien hace de mediador de ese uso, el profesor de historia quien deberá redefinir ese papel de iniciador en la lectura en diversos lenguajes y soportes. Es que moverse en la cultura digital es más complejo que en la cultura impresa. Es por esto que, parafraseando a Chartier (2012), es importante comprender que si bien nuestras sociedades quisieron ofrecer a las jóvenes generaciones todos los saberes del mundo por medio de la tecnología del doble clic, el acceso a las informaciones no basta para construir saberes. Es que los saberes no se compran, no se venden ni se regalan, se siguen construyendo igual de lentamente, bajo la sombra paciente de los maestros. En este sentido, interrogar las prácticas de los profesores de historia como mediadores entre la cultura impresa, la cultura digital y su propia cultura empírica ha sido el objeto de este artículo.

\section{REFERENCIAS}

ADELL, Jordi; BERNABÉ, Iolanda. Los libros de texto de la escuela en red. Perspectiva CEP, n. 11, p. 21-33, 2006.

AYUSO, Maria Luz; MASSONE, Marisa; ROMERO, Nancy. Mutaciones en las prácticas de lectura, escritura y estudio en un contexto de aprendizaje virtual. In: JORNADAS: "LA LECTURA Y LA ESCRITURA EN LA FORMACIÓN ACADÉMICA, DOCENTE Y PROFESIONAL”, 9, 10 y 11 jun. 2011, Argentina: Universidad Nacional de General Sarmiento (UNGS); Universidad Tecnológica Nacional (UTN), 2012.

BRAGINSKI, Ricardo. Polémica por el recorte en la compra de libros de texto para las escuelas. Clarín, Buenos Aires, 25 oct. 2018. Disponible en: https://www.clarin. com/sociedad/polemica-recorte-compra-libros-texto-escuelas_0_LCUkwLlVK. html. Acceso el: 11 nov. 2018.

CATTARUZZA, Alejandro. Los usos del pasado: la historia y la política argentinas en discusión, 1910-1945. Buenos Aires: Sudamericana, 2007.

CAVALLO, Guglielmo; CHARTIER, Roger. Historia de la lectura en el mundo occidental. Buenos Aires: Taurus, 2011.

CHARTIER, Anne-Marie. La lectura y la escritura escolares ante el desafío de las nuevas tecnologías. In: GOLDÍN, Daniel; KRISCAUTZKY, Mariana.; PERELMAN, Flora. Las TIC en la escuela, nuevas herramientas para viejos y nuevos problemas. México: Océano Travesía, 2012. p. 157-182.

DE CERTEAU, Michel. La invención de lo cotidiano. I. Artes de hacer. México: Universidad Iberoamericana, 2007. 
DUSSEL, Inés. La escuela debería ser el espacio de lo difícil pero importante. $\mathrm{La}$ Nación, 21 agosto 2016.

DÍAZ ARGÜERO, Celia. Libros de texto y biblioteca: un libro o muchos materiales. In: BONILLA, Elisa; GOLDÍN, Daniel; SALABERRIA, Ramón. Bibliotecas y escuelas: retos y posibilidades en la sociedad del conocimiento. México: Océano Travesía, 2008. p. 185-208.

DOUEIHI, Milad. La gran conversión digital. Buenos Aires: FCE, 2010.

ECO, Umberto. Lector in fabula: la cooperación interpretativa en el texto narrativo. Barcelona: Lumen, 1981.

ECO, Umberto. El libro de texto como maestro. La Nación, Buenos Aires, 23 jul. 2004.

ESCOLANO, Agustín. El libro escolar y la cultura de la educación. In: ESCOLANO, Agustín. Currículum editado y sociedad del conocimiento: texto, multimedialidad y cultura de la escuela. Valencia: Tirant lo Blanch, 2006.

ESCOLANO, Agustín. El manual como texto. Pro-Posições, Campinas: Unicamp, v. 23, n. 3 (69), p. 33-50, 2012.

FERREIRO, Emilia. Pasado y presente de los verbos leer y escribir. Buenos Aires: FCE, 2001.

FINOCCHIO, Silvia. Memoria, historia y educación en Argentina: de aprender de memoria a enseñar para la memoria de la historia reciente. In: PAGÉS, Joan; GONZÁLEZ, María Paula (coord.). Historia, memoria i ensenyament de la historia: perspectives europees i llatinoamericanes. Barcelona: Universitat Autónoma de Barcelona, 2009.

FRIERA, Silvina. Es un error pensar que los censores eran estúpidos. Entrevista de Robert Darnton. Página 12, Buenos Aires, 9 nov. 2015.

HÉBRARD, Jean. Lectores autónomos, ciudadanos activos. (Conferencia dada en el Ministerio de Educación de la Nación). Buenos Aires, 2000.

IBARRA, Diego. Canal Encuentro: una nueva pantalla en busca de todos los públicos. 2013. Disponible en: http://www.soc.unicen.edu.ar/index.php/component/content/article/112-newsletter/n23/1009-articulo-diego-ibarra. Acceso el: 31 jul. 2018 .

LANZA, Hilda; FINOCCHIO, Silvia. Curriculum presente ciencia ausente: la enseñanza de la historia en la Argentina de hoy. Tomo III. Buenos Aires: Miño y Dávila, 1993.

LION, Carina; PEROSI, Verónica. Conocimiento, hipertexto y enseñanza: perspectivas interpeladoras para el análisis crítico. In: SEMINARIO "MANUALES, LIBROS POR ÁREAS E ITINERARIOS HIPERTEXTUALES EN LA HISTORIA RECIENTE DE LA EDUCACIÓN. 1958-2008”, Universidad Nacional de Luján, 2012. 
MARTÍNEZ BONAFÉ, Jaume; RODRÍGUEZ RODRÍGUEZ, Jesús. El curriculum y el libro de texto: una dialéctica siempre abierta. In: GIMENO SACRISTÁN, José (comp.). Saberes e incertidumbres sobre el currículum. Madrid: Morata, 2010. p. 246-268.

MASSONE, Marisa. Enseñar a leer y escribir en Historia: los cambios en un contexto de transición cultural. Clío \& Asociados, n. 16, p. 152-165, 2012.

MIGUEZ, Eduardo José. Reflexiones sobre la enseñanza de la Historia y el uso de fuentes en la escuela media argentina. Propuesta Educativa, Buenos Aires: Flacso, n.7, p. 15-20, 1992.

PASCUAL, Liliana (dir.). Las políticas de provisión de libros de texto a las escuelas secundarias. Buenos Aires: Ministerio de Educación, Dirección Nacional de Información y Evaluación de la Calidad Educativa (DiNIECE). Serie Informes de Investigación, n. 6, enero 2012.

PERELMAN, Flora. El papel de la reflexión en la búsqueda de información en Internet. In: RAGUSEO, Carla. Materiales didácticos en la encrucijada: entre el modelo Wikipedia y la integración de las TICs en los libros de texto. 2013. Disponible en: https://www.researchgate.net/publication/312911405_Materiales_ didacticos_en_la_encrucijada_entre_el_modelo_Wikipedia_y_la_integracion_ de_las_TICs_en_los_libros_de_texto. Acceso en: 31 jul. 2018.

RAGUSEO, Carla. Materiales didácticos en la encrucijada: entre el modelo Wikipedia y la integración de las TICs en los libros de texto. 2013. Disponible en: https:// www.researchgate.net/publication/312911405_Materiales_didacticos_en_la_encrucijada_entre_el_modelo_Wikipedia_y_la_integracion_de_las_TICs_en_los_ libros_de_texto. Acceso en: 31 jul. 2018.

ROCKWELL, Elsie. La lectura como práctica cultural: conceptos para el estudio de los libros escolares. Revista Educação e Pesquisa, São Paulo: Faculdade de Educação, Universidade de São Paulo (USP), v. 27, n. 1, p. 11-26, jun. 2001.

ROCKWELL, Elsie. Los usos magisteriales de la lengua escrita. Nueva Antropología, v. XII, n. 42, p. 43- 55, 1992.

ROMERO, Nancy. Nuevos usos del texto escolar en la escuela primaria. In: FINOCCHIO, Silvia; ROMERO, Nancy (comp.). Saberes y prácticas escolares. Rosario: Homo Sapiens, 2011. p. 117-151.

SILVA, Jeferson Rodrigo da. As pesquisas sobre os usos do livro didático de história no início do século XXI. In: VIII ENCONTRO NACIONAL PERSPECTIVAS DO ENSINO DE HISTORIA, 8.; ENCONTRO INTERNACIONAL DE ENSINO DE HISTORIA, 3., 2012, Faculdade de Educação, Universidade Estadual de Campinas (Unicamp). Campinas, SP, Brasil, 2012.

TOSI, Carolina L. Libros de texto y mercado editorial en la Argentina (1960-2006): estudio diacrónico de los aspectos polifónicos-argumentativos para la construcción 
del saber en libros de texto de nivel medio en tres disciplinas y su relación con las políticas editoriales. 2012. Disponible en: http://repositorio.filo.uba.ar/handle/filodigital/1476. Acceso en: 31 jul. 2018.

VALLS MONTÉS, Rafael. Los estudios sobre los manuales escolares de Historia y sus nuevas perspectivas. Didáctica de las Ciencias Experimentales y Sociales, n. 15, p. 23-36, 2001.

VASILACHIS, Irene. La investigación cualitativa. In: VASILACHIS, Irene (coord.). Estrategias de investigación cualitativa. Barcelona: Gedisa, 2006.

VERÓN, Eliseo. Esto no es un libro. Barcelona: Gedisa, 1999.

\section{NOTAS}

${ }^{1}$ Profesora y Licenciada en Historia egresada de la Universidad de Buenos Aires y Especialista en Currículum y prácticas escolares y en Lectura, escritura y educación egresada de la Facultad Latinoamericana de Ciencias Sociales. Doctoranda con Orientación en Educación, Facultad de Filosofía y Letras, Universidad de Buenos Aires. Es Profesora Adjunta Regular de la cátedra Didáctica Especial y Prácticas de la Enseñanza de la Historia” en la carrera de Historia (FFyL, UBA) y Capacitadora de docentes, directivos y bibliotecarios de escuela primaria en Escuela de Maestros.

${ }^{2}$ En 2018, el Decreto 386/2018 estableció el fin del Programa Conectar Igualdad y su reemplazo por el Plan Aprender Conectados, cuyo equipamiento no será de los estudiantes sino de las escuelas.

${ }^{3}$ La Ley de Educación Sexual Integral (2006) propone una transversalización de sus contenidos.

${ }^{4}$ La Nueva Escuela Secundaria (NES) redujo las horas de historia a partir de 2014.

${ }^{5}$ El Ciclo Básico Común constituye el primer año de ingreso a la Universidad de Buenos Aires (UBA) y tiene una versión a distancia, UBA XXI.

${ }^{6} \mathrm{El}$ presupuesto 2019 tiene prevista una partida cinco veces menor en términos nominales, sin considerar la inflación estimada en torno del 50\%, para la compra estatal de libros de texto (BRAGINSKI, Clarín, 25 oct. 2018).

Artículo recibido el 13 de noviembre de 2018. Aprobado el 23 de enero de 2019. 